\title{
Microbiome Dynamics During Chemoradiotherapy for Anal Cancer
}

Daniel Lin ${ }^{1 a}$, Molly B. El Alamª, Joseph Abi Jaoude ${ }^{1}$, Ramez Kouzy ${ }^{1}$, Jae L. Phan ${ }^{1}$, Jacob H. Elnaggar², Brianna Resendiz ${ }^{1}$, Andrea Y. Delgado Medrano ${ }^{1}$, Erica Lynn", Nicholas D. Nguyen ${ }^{1}$, Sonal S. Noticewala ${ }^{1}$, Geena G. Mathew ${ }^{1}$, Emma B. Holliday ${ }^{1}$, Bruce D. Minsky ${ }^{1}$, Prajnan Das ${ }^{1}$, Van K. Morris ${ }^{3}$, Cathy Eng ${ }^{4}$, Melissa P. Mezzari ${ }^{5}$, Joseph F. Petrosino ${ }^{5}$, Nadim J. Ajami ${ }^{6}$, Ann H. Klopp ${ }^{1}$, Cullen M. Taniguchi ${ }^{1 \mathrm{~b}}$ and Lauren E. Colbert ${ }^{1 b}$

${ }^{1}$ Department of Radiation Oncology, University of Texas MD Anderson Cancer Center, Houston TX.

${ }^{2}$ Department of Microbiology, Immunology, and Parasitology, Louisiana State University Health Sciences Center, New Orleans LA.

${ }^{3}$ Department of Gastrointestinal Medical Oncology, University of Texas MD Anderson Cancer Center, Houston TX.

${ }^{4}$ Division of Hematology and Oncology, Vanderbilt-Ingram Cancer Center, Nashville TN.

${ }^{5}$ Department of Molecular Virology and Microbiology, Baylor College of Medicine, Houston TX.

${ }^{6}$ Department of Genomic Medicine, University of Texas MD Anderson Cancer Center, Houston TX.

${ }^{a}$ These authors contributed equally

${ }^{\mathrm{b}}$ Shared corresponding authorship 
Corresponding authors: Cullen Taniguchi, Lauren Colbert

Cullen Taniguchi, MD, PhD

1515 Holcombe Blvd, Unit 1050

Houston, TX 77030-4009

(713) $745-5269$

CTaniguchi@mdanderson.org

Lauren E. Colbert, MD, MSCR

1515 Holcombe Blvd, Unit 1052

Houston, TX 77030-4009

(832) 652-6033

LColbert@mdanderson.org

Word count: 2982 


\section{Key Points}

QUESTION: How does the squamous cell anal tumor microbiome change during chemoradiotherapy, and how do these changes influence treatment-related toxicity?

FINDINGS: Prospective longitudinal characterization of anal cancer patients revealed significant modulation of the local tumor microbiome in response to chemoradiotherapy including shifts in overall composition and differential enrichment of key taxa.

Additionally, enrichment of specific taxa at baseline was associated with increased levels of treatment-related toxicities by the end of treatment.

MEANING: The anal tumor microbiome is significantly altered by chemoradiotherapy and could potentially serve as a biomarker for treatment-related toxicities. 


\section{Abstract}

IMPORTANCE: Patients with localized squamous cell carcinoma of the anus (SCCA) who experience treatment toxicity or recurrences have few therapeutic options. Investigation into the microbiome's influence on treatment toxicity or its potential use as a predictive biomarker in this rare disease could improve these patients' outcomes.

OBJECTIVE: To longitudinally characterize the SCCA tumor microbiome and assess its association with treatment-related toxicities.

DESIGN: Prospective cohort study.

SETTING: Single tertiary cancer center.

PARTICIPANTS: Twenty-two patients with biopsy-confirmed non-metastatic SCCA receiving standard-of-care chemoradiotherapy as part of an Institutional Review Boardapproved study from April 2017 to July 2019.

MAIN OUTCOMES AND MEASURES: Diversity and taxonomic characterization of the SCCA microbiome throughout chemoradiotherapy using swab-based anorectal microbial specimen collection and 16S rRNA gene sequencing.

RESULTS: Twenty-two SCCA patients were included in this study with a median (range) age of 58.5 (39-77), and 18 (82\%) were women. Alpha diversity remained 
relatively stable throughout chemoradiotherapy, except for decreases in the Chao1 $(P=0.03)$ and Observed Features $(P=0.03)$ indices at week 5 relative to baseline. Tumor microbial compositions measured using weighted UniFrac changed significantly by the end of treatment $(P=0.03)$. Linear discriminant analysis effect sizes revealed differential enrichment of bacteria at specific time points, including the enrichment of Clostridia at both baseline and follow-up and the enrichment of Corynebacterium at week 5. Patients experiencing high toxicity at week 5 had higher relative abundances of Clostridia, Actinobacteria, and Clostridiales at baseline ( $P=0.03$ for all).

CONCLUSIONS AND RELEVANCE: Our study presents the first longitudinal characterization of the SCCA microbiome throughout chemoradiation. The tumor microbiome undergoes significant changes during and after chemoradiotherapy, and patient-reported toxicity levels are associated with patients' microbial profiles. Further studies into these microbial characterizations and associations are needed to elucidate the tumor microbiome's role in predicting treatment-related outcomes for SCCA patients. 


\section{Introduction}

Squamous cell carcinoma of the anus (SCCA) is a rare gastrointestinal cancer that is linked to prior human papillomavirus (HPV) infections in approximately $90 \%$ of cases. ${ }^{1}$ The standard-of-care treatment for patients with localized SCCA is chemoradiotherapy (CRT) which leads to 5-year survival rates of $75 \% .^{2}$ However, 30 $40 \%$ of patients with advanced SCCA experience local recurrence or treatment-related toxicity, for which there are no effective therapeutic options. ${ }^{3-7}$ Despite the use of HPV vaccines, the incidence and morbidity from SCCA continue to rise. ${ }^{8}$

The human microbiome influences the oncogenesis and treatment response of many cancers, including gastrointestinal cancers, ${ }^{9-11}$ through the modulation of inflammation, cell proliferation, and metabolism. ${ }^{12,13}$ Clinical and preclinical data suggest that gut microbiota are direct modulators of therapy response and toxicity. ${ }^{14-18}$

Previous studies have delineated the microbiomes of HPV-driven cancers of the cervix and oropharynx, but the role of microbiota in SCCA remains unknown. ${ }^{19-21}$ Studies in cervical cancer revealed significant associations between the gut microbiome and treatment-related toxicity. ${ }^{21,22}$ However, little is known about the microbiome's influence on treatment in SCCA and whether it can be used as a predictor of patientreported toxicity. Therefore, we sought to longitudinally characterize the tumor microbiome and its relationship to acute gastrointestinal toxicity in SCCA patients undergoing modern CRT.

\section{Methods}

\section{Patients}


Anorectal tumor swabs were prospectively collected from SCCA patients receiving standard-of-care treatment as part of an Institutional Review Board-approved study (protocol \#2014-0543) at M.D. Anderson Cancer Center from April 2017 to July 2019. Patients with biopsy-confirmed non-metastatic SCCA with a palpable tumor were included in the study. Patients with a history of abdominal or pelvic radiotherapy were excluded. Written informed consent was obtained from all patients. Eligible patients received intensity-modulated radiotherapy (IMRT), volumetric modulated arc therapy (VMAT), or proton therapy with concurrent chemotherapy. All patients received a minimum radiation dose of 46 Gy in 23 fractions over 5 weeks. Patients' demographic data were collected from medical records.

\section{Patient-Reported Outcomes and Adverse Events}

Patients completed the bowel subdomain of the Expanded Prostate Cancer Index Composite (EPIC) questionnaire before (baseline), during (weeks 1, 3, and 5), and after treatment (week 12 [follow-up]) as described previously. ${ }^{23}$ The EPIC bowel subdomain is divided into "Function" and "Bother" subdomains, each comprising of 7 questions. To highlight the differences in microbial composition at each time point, we calculated a patient-reported outcome score for each patient by comparing the patient's EPIC score to the median. Patients with EPIC scores greater than the median had low toxicity, and those with lower scores had high toxicity. At the same time points, a physician assigned each patient a Common Terminology Criteria for Adverse Events (CTCAE; version 5.0) score for anal dermatitis, and patients were stratified based on scores of 0-1 and 2-3. 


\section{S rRNA Gene Sequencing}

Anorectal swab samples were collected immediately before (baseline), during (weeks 1, 3, and 5), and after treatment (week 12 [follow-up]) (Figure 1A). Week 1 samples were collected after patients had received at minimum 1 fraction of radiotherapy. A digital rectal exam was performed with a sterile gloved finger to palpate the anal tumor, after which an Isohelix DNA Buccal Swab (Isohelix, SK-2S) was used to collect the tissue and fecal material. Samples were stabilized using BuccalFix DNA Stabilization solution (Isohelix, BFX-25) within 1 hour of collection and stored at $-80^{\circ} \mathrm{C}$ until DNA isolation was performed using the MoBIO PowerSoil kit (Qiagen, 12855-50).

The 16S rRNA gene amplification and sequencing methods were adapted from the Human Microbiome Project and Earth Microbiome Project. ${ }^{24}$ The V4 region of the 16S rRNA marker gene was PCR-amplified using a 515F-806R primer pair. The Alkek Center for Metagenomics and Microbiome Research at Baylor College of Medicine performed the $16 \mathrm{~S}$ rRNA gene sequencing using the Illumina MiSeq platform and a 2x250bp paired-end protocol.

\section{Microbiome Sequencing Analysis}

To analyze the 16S rRNA gene reads, we utilized the QIIME2 microbiome bioinformatics platform (v2019.10). ${ }^{25}$ A sampling depth of 9160 sequences per sample was used for downstream comparative analysis. Sequence quality control and amplicon sequence variant feature table construction were performed using denoising via DADA2. ${ }^{26}$ Phylogenetic reference tree construction was performed using the SILVA 128 
database, which served as the reference tree backbone for fragment insertion. ${ }^{27}$

Taxonomic identification was assigned using a naïve Bayes classifier trained using the SILVA 132 database.

\section{Microbial Diversity Metrics}

We analyzed the 16S rRNA sequencing data using 7 different alpha diversity metrics. The Shannon diversity index accounts for richness and evenness of taxa within a sample. The inverse Simpson diversity index measures the relative abundance of species that make up the richness. ${ }^{28,29}$ The Chao1 diversity index accounts for the number of rare taxa likely missed owing to undersampling. ${ }^{30}$ Faith phylogenetic diversity (PD) accounts for the phylogenetic differences between species in a sample. ${ }^{31}$ The Fisher index quantifies the relationship between the number and abundance of each species in a sample. ${ }^{32}$ Pielou evenness index calculates the proportions of individual species within a sample population. ${ }^{33}$ Finally, Observed Features provides a count of species with at least one read. ${ }^{34}$

\section{Microbial Composition}

Linear discriminant analysis (LDA) effect size (LEfSe) was used to identify bacterial taxa that were differentially enriched in samples at baseline as compared to week 5 and at week 5 as compared to follow-up. ${ }^{35}$ An LDA score cut-off of 4.0 was used. The alpha value for the Kruskal-Wallis test among classes was set at 0.05 . Weighted and unweighted UniFrac distances and Bray-Curtis dissimilarity were used to generate coordinates for each sample. Principal coordinate analysis was used to 
visualize similarities and dissimilarities between time point groups. Distances between coordinate groups were compared using permutational multivariate analysis of variance (PERMANOVA). We used LefSe with an LDA score cut-off of 4.0 to assess the differences in the baseline microbial profiles of patients with low and high toxicity at the end of treatment.

\section{Statistical Analysis}

We used descriptive statistics to summarize patients' demographic and clinical characteristics. To assess changes in microbiome diversities, we used Wilcoxon signedrank tests to compare the alpha diversity indices at weeks 1,3 , and 5 and follow-up to those at baseline. We built a linear mixed model using time as the independent predictor of diversity to include patients who did not have samples available at all time points $(n=14)$. We used individual patients as a random effect and an interaction term of baseline diversity and time as the main covariate. We used a Wilcoxon signed-rank test to detect significant differences in the relative abundances of taxa identified using LEfSe throughout treatment.

We compared the alpha diversity indices between patients with high or low toxicity using a Wilcoxon rank-sum test. We assessed the differences in identified taxa between the two toxicity groups using a Wilcoxon rank-sum test.

We compared patients' clinical and demographic characteristics according to their CTCAE scores and EPIC scores. Finally, we tested for associations between baseline alpha diversity and clinical characteristics using the Kruskal-Wallis test and Spearman correlation. Statistical significance was set at an alpha of $5 \%$ for a two-sided 
$P$ value. All analyses were performed using QIIME2 (v2019.10) and Rstudio Orange Blossom.

\section{Results}

\section{Patient Characteristics}

The study included 22 patients (18 women [82\%] and 4 men [18\%]), whose median age was 58.5 years (range, 39-77 years). Patients' baseline characteristics are shown in Table 1. Most patients received chemotherapy with cisplatin and 5-FU (18 [86\%]) and underwent IMRT or VMAT (19 [91\%]). Patients received a median radiation dose of 54 Gy over a median of 27 fractions. During the study, 7 patients (33\%) received antibiotics. Baseline swab samples were collected from 21 patients; week 1 samples, from 19 patients; week 3 samples, from 18 patients; week 5 samples, from 14 patients; and follow-up samples, from 9 patients (Supplemental Table 1). Patients' clinical characteristics were not significantly associated with either toxicity measurement. Additionally, baseline alpha diversity was not significantly associated with any patient characteristics.

\section{Tumor Microbiome Characteristics}

Alpha diversity measurements remained relatively stable throughout treatment, with the Shannon, Pielou, Simpson, inverse Simpson, and Faith PD indices showing no significant changes in community richness or evenness; however, Observed Features and Chao1 indices revealed significant decreases as compared to baseline (Figure 1B,C, Supplemental Table 2). Linear mixed modeling using time as a predictor of 
medRxiv preprint doi: https://doi.org/10.1101/2021.09.07.21263233; this version posted September 16, 2021. The copyright holder for this

decreased diversity revealed similar trends. Shannon and Pielou indices did not show a significant association with time as a predictor (Figure 1D,E). However, when accounting for high or low baseline diversity, patients with higher baseline Observed Features, Chao1 diversity, and Faith PD indices tended to have faster declines in diversity $(P<0.05$; Supplemental Table 3).

Beta diversity analysis, accounting for differences in the abundance of taxa and phylogenetic relatedness, demonstrated significant shifts in the overall community composition from baseline to week 5 . The weighted UniFrac distance matrices generated from baseline and week 5 samples are illustrated in Figure 2A. A comparison of these distance coordinates revealed significant changes in the overall microbial compositions at week 5 as compared to baseline $(P=0.032)$. Comparisons of the baseline and week 5 samples using unweighted UniFrac distances and Bray-Curtis index yielded similar results (Supplemental Table 4).

LEfSe identified 16 taxa that were differentially enriched at baseline (6 taxa) or week 5 (10 taxa) (Figure 2B). The relative abundances of 11 of these taxa significantly differed between baseline and week 5 (Supplemental Table 5). Upon closer inspection, the top 3 taxa enriched at baseline (Firmicutes [phylum], Clostridia [class], and Clostridiales [order]) were hierarchically related. Similarly, the top 5 taxa enriched at week 5 (Actinobacteria [phylum], Actinobacteria [class], Corynebacteriales [order], Corynebacteriaceae [family], and Corynebacterium [genus]) were also related. The weighted UniFrac profiles of the week 5 and follow-up samples did not differ significantly $(P=0.210)$ (Figure 2C). LEfSe revealed that some taxa enriched at follow-up were the same as those previously enriched at baseline when both were compared with week 5 . 
Follow-up samples had greater abundances of Firmicutes (phylum), Clostridiales (order), and Clostridia (class) when compared with week 5 samples (Figure 2D). Furthermore, the top 7 taxa enriched at week 5 as compared with follow-up were identical to the top 7 taxa enriched at week 5 when compared with baseline.

The relative abundances of Clostridia (class) and Clostridales (order) decreased during CRT ( $P=0.033$ for both) but increased by follow-up ( $P=0.004$ for both) (Figure 2E, Supplemental Table 5). Similarly, the relative abundances of Corynebacteriales (order), Corynebacteriaceae (family), and Corynebacterium (genus) increased during treatment ( $P=0.002,0.002$, and 0.001 , respectively) but returned to baseline levels by follow-up ( $P=0.002,0.002$, and 0.006 , respectively). The relative abundances of Finegoldia (genus) and Subdoligranulum (genus) did not change during treatment but increased following treatment $(P=0.033$ and 0.006 , respectively). The relative abundance of Actinobacteria (class) increased during treatment $(P=0.003)$ but did not change after treatment (Figure 2F). These findings indicate that although the composition of the microbiome changes during treatment, there is a period of microbial restoration following treatment during which the local anal microbiome begins to resemble the baseline microbiome.

\section{CTCAE Scores and Patient-Reported Toxicity}

16 patients had CTCAE scores of $2-4$, and 3 had scores of $0-1$. Of the 12 patients who answered the EPIC questionnaire, 6 had low scores and 6 had high scores. Baseline alpha diversity did not differ significantly between patients with CTCAE scores of 2-4 or 0-1 at week 5 (Figure 3A), except that patients with higher CTCAE 
scores had a significantly higher median Pielou index at baseline (0.75 vs. 0.69;

$P=0.02)$ (Figure 3B). Baseline alpha diversity did not differ significantly between patients with low or high EPIC scores (Figure 3C, D).

LEfSe identified several differences in the baseline abundances of species in samples from patients with low or high toxicity at week 5 . Patients with low toxicity at week 5 had higher levels of Sellimonas, whereas patients with high toxicity at week 5 had higher levels of Actinobacteria (phylum and class), Peptoniphilus, Clostridiales, Clostridia, and Clostridiales FamilyXI (Figure 4A). Patients with high toxicity at week 5 had significantly higher relative abundances of Clostridia, Actinobacteria (class), and Clostridiales at baseline ( $P=0.03$ for all), whereas patients with low toxicity had a significantly higher relative abundance of Sellimonas (genus; $P=0.048$ ) (Figure 4B,C,

\section{Supplemental Table 6).}

\section{Discussion}

While the microbiome has been well characterized in HPV-driven cancers, published research describing the SCCA microbiome remains scarce. ${ }^{36}$ Here, we present the first longitudinal characterization of the SCCA microbiome and its response to CRT. Alpha diversity metrics revealed relative stability within the local anal tumor microbiome throughout treatment. However, we observed a trend of decreasing alpha diversity during treatment when accounting for baseline diversity. We suspect that, with increasing patient numbers, this trend of decreasing diversity during CRT would become more prominent, as described in cervical cancer patients. ${ }^{37}$ 
In our cohort, beta diversity metrics indicated a distinct shift in the overall composition of the microbiome during CRT. Further investigation using LEfSe and relative abundance comparisons revealed 11 taxa, including Clostridiales, Corynebacteriales, and Actinobacteria (class), that were differentially enriched by the end of CRT. Many of these enriched taxa directly overlapped with the LEfSe results comparing week 5 samples to follow-up where samples exhibited similar taxa enriched at baseline. These findings suggested a period of restoration of the anal microbiome in the weeks following CRT.

Our quantitative data also offer new insight into the microbiome of SCCA patients and its association with their quality of life. Our study prospectively measured toxicity using both patient and physician assessment tools to help capture the true extent of disease- and treatment-related toxicity. Microbial diversity did not predict toxicity, but some bacterial species were significantly associated with CRT-related toxicity. LEfSe and relative abundance comparisons revealed that higher relative abundances of bacterial taxa such as Clostridia and Actinobacteria (class) at baseline were associated with increased toxicity at the end of treatment. Additional studies are needed to determine whether certain microbial species lead to increased gastrointestinal toxicity or vice-versa.

Our study suggests that CRT affects the overall composition of the SCCA microbiome and that specific microbes in the local tumor microenvironment may play a role in treatment-related toxicity. However, the mechanisms of such interactions undetermined. One such mechanism may involve the local breakdown of the epithelial barrier due to radiotherapy. The reduced epithelial integrity, change in mucosal 
medRxiv preprint doi: https://doi.org/10.1101/2021.09.07.21263233; this version posted September 16, 2021. The copyright holder for this

secretions, and damage to mucosal immune cells could enable the translocation and persistence of abnormal microbiota. ${ }^{38}$ The outgrowth of certain bacterial species on the epithelial membrane due to CRT could affect gastrointestinal and skin toxicity through inflammation and immune regulation. Furthermore, following radiotherapy, the epithelial lining can begin healing, which could allow for the return of bacteria native to the mucosa. ${ }^{39,40}$ In addition, preclinical studies suggest that the microbiome influences radiation proctitis, resulting in the modulation of cytokines, particularly interleukin $1 \beta^{41}$ The immune modulation of increased interleukin $1 \beta$ has been similarly observed in bacterial vaginosis, which is associated with HPV-driven cervical cancer. ${ }^{42}$ Lastly, radiotherapy-induced diarrhea, a common toxicity of pelvic radiotherapy, has been linked to significant shifts in the gut microbiome, with some studies suggesting that gut dysbiosis is a predictor of severe diarrhea during and after radiotherapy. ${ }^{43,44}$ These possible mechanisms require further investigation in both preclinical and clinical studies.

Multiple studies have investigated changes in microbiome profiles during pelvic radiation, but none have characterized the SCCA microbiome. ${ }^{4-45}$ Previous clinical studies have demonstrated a similar marked decrease in Firmicutes in the gut resulting from radiotherapy. ${ }^{43,46}$ Also, preclinical studies of radiation-induced rectal dysbiosis showed similar decreases in Clostridia, Clostridiales, and Firmicutes. ${ }^{41,43}$ We observed that an increased baseline level of Clostridiales was associated with higher toxicity during treatment, which is contrary to previous reports of the potential positive effects of Clostridiales during CRT for HPV-driven cervical cancer. ${ }^{22,37}$

One of the most significantly enriched bacteria in our end-of-treatment samples was Corynebacterium. Corynebacterium is believed to be largely commensal 
medRxiv preprint doi: https://doi.org/10.1101/2021.09.07.21263233; this version posted September 16, 2021. The copyright holder for this

inhabitants of human skin flora, but its role in the tumor microbiome and treatment response is unclear. However, some members of Corynebacterium, such as Corynebacterium jeikeium, may prevent oxidative damage to both itself and epidermal tissue through its acquisition of manganese necessary for the function of manganesedependent superoxide dismutase. ${ }^{47}$

The present study had some limitations. First, it was a single-institution study with a limited sample size. Thus, its results may not be generalizable to a broader population considering the known regional variations in microbial communities. ${ }^{48}$ However, given the low prevalence of SCCA, this study was the first and largest longitudinal study to analyze this population's microbiome during CRT. Second, the standard-of-care chemotherapy at our institution is cisplatin and 5-FU, which might have different toxicity and microbiome interactions than the widely used regimen of 5-FU and mitomycin-C. However, since cisplatin is the most commonly used radio-sensitizing chemotherapy for HPV-related malignancies, these data may be valuable in comparing microbiome effects between other anatomical sites such as oropharyngeal cancer or cervical cancer. Third, our study focused on acute changes occurring within a relatively short follow-up time (3 months). Additionally, half the patients did not provide patientreported outcome data at the final follow-up. The patient attrition rate might be due to the increase in loss to follow-up after the treatment was concluded at week 5. However, longitudinal sampling is one of the most robust methods to evaluate microbiome data. In addition, we used appropriate statistical analyses to account for the small sample size. Finally, in-depth research involving preclinical models could provide unique insights into the role of the microbiota in this disease, but the HPV-driven tumor and the human 
microbiome remain difficult to recapitulate in animal models. Our hypothesis-generating work is the first to shed light on the microbiome's role in SCCA and its associations with toxicity, but future studies will be essential to confirm and expand upon these findings.

In conclusion, we found that the local tumor microbiome of SCCA patients changes significantly throughout and following CRT. Our findings suggest an association between the microbial profiles and toxicity levels of SCCA patients receiving CRT. Our work highlights the microbiome's associations and potential roles in an understudied disease and underreported quality-of-life issues. Our data help provide a foundation for future research to better understand the potentially predictive and therapeutic role of microbiota in SCCA. 


\section{Acknowledgment}

Author Contributions: Dr. Cullen Taniguchi and Dr. Lauren Colbert had complete access to the data in the study and take responsibility for the integrity and accuracy of the data analysis.

Concept and design: Colbert, Taniguchi, Klopp

Acquisition, analysis, or interpretation of data: Lin, El Alam, Abi Jaoude, Kouzy, Phan, Delgado Medrano, Lynn, Elnaggar, Mathew, Holliday, Mezzari, Petrosino, Ajami, Klopp, Colbert, Taniguchi

Drafting of the manuscript: Lin, El Alam, Kouzy, Abi Jaoude, Elnaggar, Resendiz, Klopp, Colbert, Taniguchi

Critical revision of the manuscript for important intellectual content: Lin, El Alam, Abi Jaoude, Kouzy, Phan, Elnaggar, Resendiz, Delgado Medrano, Lynn, Nguyen, Noticewala, Mathew, Holliday, Minsky, Das, Morris, Eng, Mezzari, Petrosino, Ajami, Klopp, Colbert, Taniguchi

Statistical analysis: El Alam, Abi Jaoude, Kouzy, Lin

Obtained funding: Taniguchi, Colbert, Klopp

Administrative, technical, or material support: Noticewala, Mathew, Holliday, Minsky, Das, Morris, Eng, Mezzari, Petrosino, Ajami

Supervision: Taniguchi, Colbert

Conflict of Interest Disclosures: C.M.T. is on the clinical advisory board of Accuray, has a patent for oral amifostine as a radioprotectant of the upper Gl tract issued, licensed, and with royalties paid from Xerient Pharmaceuticals and PHD inhibitors as a radioprotectant of the Gl tract pending, and was the lead principal investigator of a 
multicenter trial testing the effects of high-dose SBRT with the radiomodulator, GC4419. C.M.T. is also a paid consultant for Phebra Pty, Ltd. The other authors declare no potential conflicts of interest.

Funding/Support: C.M.T. is a Khalifa Scholar supported by the Khalifa Bin Zayed Al Nahyan Foundation and is also supported by the Dodd Family Foundation. L.E.C. received funding from the University of Texas MD Anderson Cancer Center HPV-related Cancers Moonshot and Radiological Society of North America Resident/Fellow Award. Role of the Funder/Sponsor: The funding sources had no role in the design and conduct of the study; collection, management, analysis, and interpretation of the data; preparation, review, or approval of the manuscript; and decision to submit the manuscript for publication.

Additional Contributions: We thank the patients for their immeasurable contribution and the radiation oncology clinical and lab teams at the University of Texas MD Anderson Cancer Center. 


\section{References}

1. Schiffman M, Doorbar J, Wentzensen N, et al. Carcinogenic human papillomavirus infection. Nat Rev Dis Primers. 2016;2(1):16086. doi:10.1038/nrdp.2016.86

2. Franklin RA, Giri S, Valasareddy P, Lands LT, Martin MG. Comparative Survival of Patients With Anal Adenocarcinoma, Squamous Cell Carcinoma of the Anus, and Rectal Adenocarcinoma. Clinical Colorectal Cancer. 2016;15(1):47-53. doi:10.1016/j.clcc.2015.07.007

3. John M, Flam M, Palma N. Ten-year results of chemoradiation for anal cancer: Focus on late morbidity. International Journal of Radiation Oncology ${ }^{*}$ Biology ${ }^{*}$ Physics. 1996;34(1):65-69. doi:10.1016/0360-3016(95)00223-5

4. Mai SK, Welzel G, Hermann B, Bohrer M, Wenz F. Long-Term Outcome after Combined Radiochemotherapy for Anal Cancer \&ndash; Retrospective Analysis of Efficacy, Prognostic Factors, and Toxicity. Onkologie. 2008;31(5):251-257. doi:10.1159/000121362

5. Mitchell SE, Mendenhall WM, Zlotecki RA, Carroll RR. Squamous cell carcinoma of the anal canal. International Journal of Radiation Oncology ${ }^{\star}$ Biology ${ }^{\star}$ Physics. 2001;49(4):1007-1013. doi:10.1016/S0360-3016(00)01518-2

6. Ferrigno R, Nakamura RA, Ribeiro Dos Santos Novaes PE, et al. Radiochemotherapy in the conservative treatment of anal canal carcinoma: Retrospective analysis of results and radiation dose effectiveness. International 
Journal of Radiation Oncology ${ }^{*}$ Biology ${ }^{*}$ Physics. 2005;61(4):1136-1142.

doi:10.1016/j.jijobp.2004.07.687

7. Johnston MJ, Robertson GM, Frizelle FA. Management of Late Complications of Pelvic Radiation in the Rectum and Anus: A Review. Diseases of the Colon \& Rectum. 2003;46(2):247-259. doi:10.1007/s10350-004-6530-4

8. Oliveira CR, Niu YS, Einarsdottir HM, Niccolai LM, Shapiro ED. Disparities in the Epidemiology of Anal Cancer: A Cross-Sectional Time Series. Health Equity. 2020;4(1):382-385. doi:10.1089/heq.2020.0021

9. Brawner KM, Morrow CD, Smith PD. Gastric Microbiome and Gastric Cancer. The Cancer Journal. 2014;20(3):211-216. doi:10.1097/PPO.0000000000000043

10. Zitvogel L, Galluzzi L, Viaud S, et al. Cancer and the gut microbiota: an unexpected link. Sci Trans/ Med. 2015;7(271):271ps1. doi:10.1126/scitransImed.3010473

11. Gopalakrishnan V, Spencer CN, Nezi L, et al. Gut microbiome modulates response to anti-PD-1 immunotherapy in melanoma patients. Science. 2018;359(6371):97103. doi:10.1126/science.aan4236

12. Ridlon JM, Kang DJ, Hylemon PB, Bajaj JS. Bile acids and the gut microbiome. Curr Opin Gastroenterol. 2014;30(3):332-338.

doi:10.1097/MOG.0000000000000057 
13. Wroblewski LE, Peek RM, Coburn LA. The Role of the Microbiome in Gastrointestinal Cancer. Gastroenterology Clinics of North America. 2016;45(3):543-556. doi:10.1016/j.gtc.2016.04.010

14. lida N, Dzutsev A, Stewart CA, et al. Commensal Bacteria Control Cancer Response to Therapy by Modulating the Tumor Microenvironment. Science. 2013;342(6161):967-970. doi:10.1126/science.1240527

15. Vetizou M, Pitt JM, Daillere R, et al. Anticancer immunotherapy by CTLA-4 blockade relies on the gut microbiota. Science. 2015;350(6264):1079-1084. doi:10.1126/science.aad1329

16. Sivan A, Corrales L, Hubert N, et al. Commensal Bifidobacterium promotes antitumor immunity and facilitates anti-PD-L1 efficacy. Science. 2015;350(6264):1084-1089. doi:10.1126/science.aac4255

17. Routy B, Le Chatelier E, Derosa L, et al. Gut microbiome influences efficacy of PD1-based immunotherapy against epithelial tumors. Science. 2018;359(6371):9197. doi:10.1126/science.aan3706

18. Helmink BA, Khan MAW, Hermann A, Gopalakrishnan V, Wargo JA. The microbiome, cancer, and cancer therapy. Nat Med. 2019;25(3):377-388. doi:10.1038/s41591-019-0377-7

19. Gillet E, Meys JFA, Verstraelen $\mathrm{H}$, et al. Association between Bacterial Vaginosis and Cervical Intraepithelial Neoplasia: Systematic Review and Meta-Analysis. PLoS One. 2012;7(10). doi:10.1371/journal.pone.0045201 
20. Guerrero-Preston R, Godoy-Vitorino F, Jedlicka A, et al. 16S rRNA amplicon sequencing identifies microbiota associated with oral cancer, human papilloma virus infection and surgical treatment. Oncotarget. 2016;7(32):51320-51334. doi:10.18632/oncotarget.9710

21. Sims TT, El Alam MB, Karpinets TV, et al. Gut microbiome diversity is an independent predictor of survival in cervical cancer patients receiving chemoradiation. Commun Biol. 2021;4(1):237. doi:10.1038/s42003-021-01741-x

22. Mitra A, Grossman Biegert GW, Delgado AY, et al. Microbial Diversity and Composition Is Associated with Patient-Reported Toxicity during Chemoradiation Therapy for Cervical Cancer. International Journal of Radiation Oncology ${ }^{\star}$ Biology ${ }^{\star}$ Physics. 2020;107(1):163-171. doi:10.1016/j.jijrobp.2019.12.040

23. Kouzy R, Abi Jaoude J, Lin D, et al. Patient-Reported Gl Outcomes in Patients With Anal Cancer Receiving Modern Chemoradiation. JCO Oncology Practice. Published online July 1, 2020:OP.20.00122. doi:10.1200/OP.20.00122

24. Human Microbiome Project Consortium. A framework for human microbiome research. Nature. 2012;486(7402):215-221. doi:10.1038/nature11209

25. Bolyen E, Rideout JR, Dillon MR, et al. Reproducible, interactive, scalable and extensible microbiome data science using QIIME 2. Nat Biotechnol. 2019;37(8):852-857. doi:10.1038/s41587-019-0209-9 
26. Nearing JT, Douglas GM, Comeau AM, Langille MGI. Denoising the Denoisers: an independent evaluation of microbiome sequence error-correction approaches.

PeerJ. 2018;6:e5364. doi:10.7717/peerj.5364

27. Pruesse E, Quast C, Knittel K, et al. SILVA: a comprehensive online resource for quality checked and aligned ribosomal RNA sequence data compatible with ARB. Nucleic Acids Research. 2007;35(21):7188-7196. doi:10.1093/nar/gkm864

28. Lepr $\square$ tre A, Mouillot D. A comparison of species diversity estimators. Population Ecology. 1999;41(2):203-215. doi:10.1007/s101440050024

29. Hill MO. Diversity and Evenness: A Unifying Notation and Its Consequences. Ecology. 1973;54(2):427-432. doi:10.2307/1934352

30. Chao A. Non-Parametric Estimation of the Number of Classes in a Population. Scandinavian Journal of Statistics. 1984;11:265-270.

31. Faith DP. Conservation evaluation and phylogenetic diversity. Biological Conservation. 1992;61(1):1-10. doi:10.1016/0006-3207(92)91201-3

32. Fisher RA, Corbet AS, Williams CB. The Relation Between the Number of Species and the Number of Individuals in a Random Sample of an Animal Population. The Journal of Animal Ecology. 1943;12(1):42. doi:10.2307/1411

33. Pielou EC. The measurement of diversity in different types of biological collections. Journal of Theoretical Biology. 1966;13:131-144. doi:10.1016/00225193(66)90013-0 
34. Prodan A, Tremaroli V, Brolin H, Zwinderman AH, Nieuwdorp M, Levin E.

Comparing bioinformatic pipelines for microbial 16S rRNA amplicon sequencing.

Seo J-S, ed. PLoS ONE. 2020;15(1):e0227434. doi:10.1371/journal.pone.0227434

35. Segata N, Izard J, Waldron L, et al. Metagenomic biomarker discovery and explanation. Genome Biol. 2011;12(6):R60. doi:10.1186/gb-2011-12-6-r60

36. Lin D, Kouzy R, Abi Jaoude J, et al. Microbiome factors in HPV-driven carcinogenesis and cancers. Spindler KR, ed. PLoS Pathog. 2020;16(6):e1008524. doi:10.1371/journal.ppat.1008524

37. El Alam MB, Sims TT, Kouzy R, et al. A prospective study of the adaptive changes in the gut microbiome during standard-of-care chemoradiotherapy for gynecologic cancers. PLoS One. 2021;16(3):e0247905. doi:10.1371/journal.pone.0247905

38. Moens E, Veldhoen M. Epithelial barrier biology: good fences make good neighbours: Epithelial barrier biology. Immunology. 2012;135(1):1-8. doi:10.1111/j.1365-2567.2011.03506.x

39. Liu J, Liu C, Yue J. Radiotherapy and the gut microbiome: facts and fiction. Radiat Oncol. 2021;16(1):9. doi:10.1186/s13014-020-01735-9

40. Sonis ST, Elting LS, Keefe D, et al. Perspectives on cancer therapy-induced mucosal injury: Pathogenesis, measurement, epidemiology, and consequences for patients. Cancer. 2004;100(S9):1995-2025. doi:10.1002/cncr.20162 
41. Gerassy-Vainberg S, Blatt A, Danin-Poleg Y, et al. Radiation induces proinflammatory dysbiosis: transmission of inflammatory susceptibility by host cytokine induction. Gut. 2018;67(1):97-107. doi:10.1136/gutjnl-2017-313789

42. Mitchell C, Marrazzo J. Bacterial vaginosis and the cervicovaginal immune response. Am J Reprod Immunol. 2014;71(6):555-563. doi:10.1111/aji.12264

43. Wang A, Ling Z, Yang Z, et al. Gut microbial dysbiosis may predict diarrhea and fatigue in patients undergoing pelvic cancer radiotherapy: a pilot study. PLoS One. 2015;10(5):e0126312. doi:10.1371/journal.pone.0126312

44. Al-Qadami G, Van Sebille Y, Le H, Bowen J. Gut microbiota: implications for radiotherapy response and radiotherapy-induced mucositis. Expert Review of Gastroenterology \& Hepatology. 2019;13(5):485-496.

doi:10.1080/17474124.2019.1595586

45. Jiang L, Li B, Zhang Y, et al. Influence of Pelvic Intensity-Modulated Radiation Therapy With Concurrent Cisplatin-Based Chemotherapy of Cervical Cancer on the Vaginal Microbiome. Front Oncol. 2021;11:615439. doi:10.3389/fonc.2021.615439

46. Nam Y-D, Kim HJ, Seo J-G, Kang SW, Bae J-W. Impact of Pelvic Radiotherapy on Gut Microbiota of Gynecological Cancer Patients Revealed by Massive Pyrosequencing. Heimesaat MM, ed. PLoS ONE. 2013;8(12):e82659. doi:10.1371/journal.pone.0082659 
medRxiv preprint doi: https://doi.org/10.1101/2021.09.07.21263233; this version posted September 16, 2021. The copyright holder for this preprint (which was not certified by peer review) is the author/funder, who has granted medRxiv a license to display the preprint in perpetuity. All rights reserved. No reuse allowed without permission.

47. Cogen AL, Nizet V, Gallo RL. Skin microbiota: a source of disease or defence?: Skin microbiota. British Journal of Dermatology. 2008;158(3):442-455. doi:10.1111/j.1365-2133.2008.08437.x

48. He Y, Wu W, Zheng H-M, et al. Regional variation limits applications of healthy gut microbiome reference ranges and disease models. Nat Med. 2018;24(10):15321535. doi:10.1038/s41591-018-0164-x 


\section{Figure Legends}

\section{Figure 1. Alpha Diversity During Chemoradiotherapy}

A, Study overview depicting the time points at which anorectal swabs were collected and patient-reported outcome questionnaires were administered.

B and C, SCCA patients' Pielou evenness (B) and Shannon diversity (C) indices did not change significantly throughout chemoradiotherapy. Wilcoxon signed-rank test was used for comparisons.

D and E, Linear mixed modeling revealed trends of high and low baseline alpha diversity metrics predicting diversity richness (D) and evenness (E).

\section{Figure 2. Beta Diversity and Taxa-Specific Changes During Chemoradiotherapy}

A, Principal coordinate analysis was used to visualize microbial composition of samples collected at baseline and week 5 using weighted UniFrac distances. PERMANOVA revealed significantly different microbial compositions at baseline and week 5 .

B, LEfSe revealed time point-specific taxa enrichment at baseline as compared to week 5 (LDA threshold, 4.0). The top 3 taxa enriched at baseline were hierarchically related, as were the top 5 taxa enriched at week 5.

C, Principal coordinate analysis was used to visualize microbial composition of samples collected at week 5 and follow-up using weighted UniFrac distances. PERMANOVA showed no significant differences in patients' microbiome profiles at week 5 as compared to follow-up.

D, LEfSe revealed time point-specific taxa enrichment at week 5 as compared to followup (LDA threshold, 4.0). The taxa enriched at week 5 as compared to follow-up were 
strikingly similar to the taxa enriched at week 5 as compared to baseline, with 7 overlapping taxa. In addition, the top 3 taxa enriched at follow-up as compared to week 5 were the same as the top 3 taxa enriched at baseline as compared to week 5 .

$\mathbf{E}$ and $\mathbf{F}$, The relative abundances of Clostridia $(\mathrm{E})$ and Actinobacteria $(\mathrm{F})$ change significantly throughout chemoradiotherapy. The abundance of Clostridia decreases significantly from baseline to week 5 but returns to its baseline level by follow-up. In contrast, the abundance of Actinobacteria increases significantly from baseline to week 5 and then decreases (though not significantly) from week 5 to follow-up. Wilcoxon signed-rank test was used for comparisons.

Figure 3. Analysis of Alpha Diversity Metrics and Quality-of-Life Measurements

A and $B$, Increased microbial richness $(A)$ and evenness $(B)$ at baseline were associated with higher CTCAE scores at week 5 . Wilcoxon rank-sum test was used for comparisons.

C and D, Microbial richness (A) and evenness $(B)$ at baseline were not associated with toxicity at week 5 . Wilcoxon rank-sum test was used for comparisons.

Figure 4. Baseline Taxonomic Enrichment May Serve as a Biomarker for Chemoradiotherapy Quality of Life at Week 5.

A, LEfSe of baseline microbial profiles revealed differences in taxa-specific enrichment between patients grouped by low and high toxicity based on EPIC scores. 
medRxiv preprint doi: https://doi.org/10.1101/2021.09.07.21263233; this version posted September 16, 2021. The copyright holder for this preprint (which was not certified by peer review) is the author/funder, who has granted medRxiv a license to display the preprint in perpetuity. All rights reserved. No reuse allowed without permission.

B and C, The relative abundances of Clostridia (B) and Actinobacteria (C) at baseline differed significantly between patients grouped by high and low toxicity based on EPIC scores. Wilcoxon rank-sum test was used for comparisons. 
Table 1. Patients' Demographic and Clinical Characteristics

No. of patients (\%), ${ }^{a}$

Characteristic

$n=22$

Age, median (range), years

$58.5(39-77)$

Sex

Female

$18(82)$

Male

$4(18)$

Race

Asian

$1(5)$

Black

$3(14)$

Other

$1(5)$

White/Caucasian

$17(77)$

Smoking status

Former smoker

$10(46)$

Never smoked

$12(55)$

Alcohol consumption

Yes

$12(57)$

No

9 (43)

$\mathrm{BMI}$, median (range), $\mathrm{kg} / \mathrm{m}^{2}$

$28.2(19.6-38.6)$

HIV status 
Positive

Negative

Nodal status

Positive

Negative

Disease stage

I

II

III

IV

Antibiotic use

Yes

No

Hospitalization $^{b}$

Yes

4 (22)

No

$14(78)$

ER visit ${ }^{\mathrm{b}}$

Yes

$9(50)$

No

$9(50)$

\section{$1(6)$}

17 (94)

$14(67)$

8 (36)

2 (9)

6 (27)

$13(59)$

1 (5)

7 (33)

$14(67)$
14 (67)

\section{IV fluids ${ }^{b}$}

version posted September 16, 2021. The copyright holder for this 
Yes

No

Radiation dose, median (range), Gy

No. of fractions, median (range)

Type of radiotherapy ${ }^{b}$

IMRT/VMAT

Proton therapy

Type of chemotherapy ${ }^{b}$

Cisplatin/5-FU

Cisplatin/capecitabine

5-FU/mitomycin C

\section{7 (39)}

$11(61)$

$54(46-58)$

27 (23-29)
19 (91)

$2(10)$

2 (10)

Abbreviations: $\mathrm{BMI}=$ Body Mass Index, HIV = Human Immunodeficiency Virus, IMRT = Intensity-modulated radiation therapy, VMAT = Volumetric Modulated Arc Therapy, 5-

$\mathrm{FU}=5$-Fluorouracil

aUnless otherwise indicated.

${ }^{b}$ Missing data due to loss to follow-up 


\section{Supplemental Table 1. Sample Availability for Each Patient at Each Time Point}

\begin{tabular}{|c|c|c|c|c|c|}
\hline$\overline{\text { Patient }}$ & Baseline & Week 1 & Week 3 & Week 5 & Follow-up \\
\hline 1 & Present & Present & Present & Present & Present \\
\hline 2 & Present & Present & Present & Present & Present \\
\hline 3 & Present & Present & Present & Present & Present \\
\hline 4 & Present & Present & Present & Present & Present \\
\hline 5 & Present & Present & Present & Absent & Absent \\
\hline 6 & Present & Present & Present & Absent & Absent \\
\hline 7 & Present & Present & Absent & Absent & Absent \\
\hline 8 & Present & Present & Present & Present & Present \\
\hline 9 & Present & Present & Present & Present & Absent \\
\hline 10 & Present & Present & Present & Present & Absent \\
\hline 11 & Present & Present & Present & Present & Present \\
\hline 12 & Present & Present & Present & Present & Present \\
\hline 13 & Present & Present & Present & Absent & Absent \\
\hline 14 & Present & Present & Present & Present & Present \\
\hline 15 & Absent & Present & Absent & Present & Present \\
\hline 16 & Present & Present & Present & Absent & Absent \\
\hline 17 & Present & Absent & Present & Present & Absent \\
\hline 18 & Present & Absent & Present & Absent & Absent \\
\hline
\end{tabular}


medRxiv preprint doi: https://doi.org/10.1101/2021.09.07.21263233; this version posted September 16, 2021. The copyright holder for this preprint (which was not certified by peer review) is the author/funder, who has granted medRxiv a license to display the preprint in perpetuity.

All rights reserved. No reuse allowed without permission.

\begin{tabular}{llllll}
19 & Present & Absent & Absent & Absent & Absent \\
20 & Present & Present & Absent & Absent & Absent \\
21 & Present & Present & Present & Present & Absent \\
22 & Present & Present & Present & Present & Absent \\
\hline
\end{tabular}


Supplemental Table 2. Diversity and Evenness Metrics at Baseline vs. Those During and After Chemoradiotherapy

Diversity/Evenness

metric

Time point Median (range) $\quad P$ value ${ }^{a}$

Shannon

Baseline $5.27(3.95-6.26) \quad$ -

Week $1 \quad 4.76(3.73-6.31) \quad 0.154$

Week $3 \quad 5.15(2.8-6.46) \quad 0.609$

Week $5 \quad 4.6(2.69-6.17) \quad 0.057$

Follow-up $\quad 5.22(4.28-5.9) \quad 0.945$

Pielou

Baseline

$0.75(0.62-0.83)$

Week 1

$0.74(0.62-0.8)$

0.609

Week 3

$0.76(0.4-0.85)$

1.00

Week 5

$0.72(0.47-0.8)$

0.127

Follow-up

$0.75(0.66-0.79)$

0.547

Simpson

Baseline

$0.95(0.85-0.98)$

Week 1

$0.93(0.8-0.98)$

0.347

Week 3

$0.95(0.59-0.98)$

0.932

Week 5

$0.92(0.69-0.97)$

0.080

Follow-up

$0.94(0.9-0.97)$

0.742

Inverse Simpson

Baseline

$1.06(1.02-1.18)$

Week 1

$1.08(1.02-1.25)$

0.325 
Week $3 \quad 1.05(1.02-1.68) \quad 0.932$

Week $5 \quad 1.09(1.03-1.45) \quad 0.080$

Follow-up $1.06(1.03-1.11) \quad 0.742$

Observed Features

Faith PD

Baseline

46.67 (34.02-

Baseline $142(83-214)$

Week $1 \quad 104(58-252) \quad 0.061$

Week $3 \quad 125.5(70-223) \quad 0.177$

Week $593(55-211) \quad 0.036$

Follow-up $130(60-183) \quad 0.441$

Week $1 \quad 37.77$ (30.45-78) 0.142

Week $3 \quad 42.9(27.98-65.6) \quad 0.090$

Week 5

$38.01(24.87-$

61.33)

0.080

$38.64(23.68-$

Follow-up

57.67)

Chao1

Baseline $153(85-232)$

Week $1 \quad 110(58-265) \quad 0.059$

Week $3 \quad 130(70-225) \quad 0.139$

Week $594(56-225) \quad \mathbf{0 . 0 3 3}$

Follow-up $138(62-189) \quad 0.441$ 
medRxiv preprint doi: https://doi.org/10.1101/2021.09.07.21263233; this version posted September 16, 2021. The copyright holder for this preprint (which was not certified by peer review) is the author/funder, who has granted medRxiv a license to display the preprint in perpetuity. All rights reserved. No reuse allowed without permission.

${ }^{\text {a}}$ Calculated using a Wilcoxon signed-rank test, as compared with baseline. 
Supplemental Table 3. Linear Mixed Model Analysis of the Interaction Effect of Time $^{\mathrm{a}}$ and Baseline Diversity on Gut Diversity Throughout Treatment

\begin{tabular}{|c|c|c|c|c|}
\hline \multirow[b]{2}{*}{ Outcome } & \multirow[b]{2}{*}{ Covariate } & \multirow[b]{2}{*}{ Estimate } & \multicolumn{2}{|l|}{$95 \%$ confidence } \\
\hline & & & interval & $P$ value \\
\hline \multirow[t]{3}{*}{ Observed Features } & Low diversity & -57.56 & $(-84.25,-30.86)$ & $<0.01$ \\
\hline & Time & -10.97 & $(-16.31,-5.56)$ & $<0.01$ \\
\hline & Low diversity:Time & 9.77 & $(1.79,17.59)$ & 0.02 \\
\hline \multirow[t]{3}{*}{ Shannon } & Low diversity & -0.63 & $(-1.10,-0.15)$ & 0.01 \\
\hline & Time & -0.17 & $(-0.28,-0.05)$ & $<0.01$ \\
\hline & Low diversity:Time & 0.09 & $(-0.09,0.26)$ & 0.32 \\
\hline \multirow[t]{3}{*}{ Simpson } & Low diversity & -0.03 & $(-0.07,0.01)$ & 0.20 \\
\hline & Time & -0.01 & $(-0.02,-0.0003)$ & 0.049 \\
\hline & Low diversity:Time & 0.01 & $(-0.01,0.02)$ & 0.38 \\
\hline \multirow[t]{3}{*}{ Inverse Simpson } & Low diversity & -0.03 & $(-0.09,0.04)$ & 0.43 \\
\hline & Time & 0.01 & $(-0.01,0.02)$ & 0.38 \\
\hline & Low diversity:Time & 0.01 & $(-0.02,0.03)$ & 0.54 \\
\hline \multirow[t]{3}{*}{ Chao1 } & Low diversity & -58.40 & $(-86.76,-30.05)$ & $<0.01$ \\
\hline & Time & -11.78 & $(-17.77,-5.66)$ & $<0.01$ \\
\hline & Low diversity:Time & 9.85 & $(1.29,18.29)$ & 0.03 \\
\hline \multirow[t]{2}{*}{ Faith PD } & Low diversity & -14.21 & $(-21.53,-6.92)$ & $<0.01$ \\
\hline & Time & -2.98 & $(-4.21,-1.73)$ & $<0.01$ \\
\hline
\end{tabular}


medRxiv preprint doi: https://doi.org/10.1101/2021.09.07.21263233; this version posted September 16, 2021. The copyright holder for this preprint (which was not certified by peer review) is the author/funder, who has granted medRxiv a license to display the preprint in perpetuity. All rights reserved. No reuse allowed without permission.

\begin{tabular}{|c|c|c|c|c|}
\hline & Low diversity:Time & 3.25 & $(1.39,5.04)$ & $<0.01$ \\
\hline \multirow[t]{3}{*}{ Pielou } & Low diversity & -0.06 & $(-0.11,-0.01)$ & 0.02 \\
\hline & Time & -0.02 & $(-0.03,-0.003)$ & 0.02 \\
\hline & Low diversity:Time & 0.01 & $(-0.004,0.03)$ & 0.12 \\
\hline
\end{tabular}


Supplemental Table 4. Beta Diversity Metrics at Baseline vs. Those During and After Chemoradiotherapy

Diversity metric $\quad$ Time point $P$ value $^{\mathrm{a}}$

\begin{tabular}{lll}
\hline Weighted Unifrac & Baseline & \multicolumn{1}{l}{ - } \\
& Week 1 & 0.127 \\
& Week 3 & 0.168 \\
& Week 5 & $\mathbf{0 . 0 3 2}$ \\
& Follow-up & 0.720 \\
Unweighted Unifrac & Baseline & - \\
& Week 1 & 0.129 \\
& Week 3 & 0.169 \\
& Week 5 & $\mathbf{0 . 0 3 5}$ \\
& Follow-up & 0.073 \\
& Baseline & - \\
Bray-Curtis & Week 1 & 0.743 \\
& Week 3 & 0.690 \\
& Week 5 & $\mathbf{0 . 0 2 7}$ \\
& Follow-up & 0.448 \\
\hline
\end{tabular}

\footnotetext{
${ }^{\mathrm{a} C a l c u l a t e d ~ u s i n g ~ p e r m u t a t i o n a l ~ m u l t i v a r i a t e ~ a n a l y s i s ~ o f ~ v a r i a n c e, ~ a s ~ c o m p a r e d ~ t o ~}$ baseline.
} 
Supplemental Table 5. Changes in the Relative Abundances of Taxa, Baseline vs. Week 5 and Week 5 vs. FollowUp

\begin{tabular}{|c|c|c|c|c|c|}
\hline \multirow[b]{3}{*}{ Taxa } & \multicolumn{3}{|c|}{ Median (range) } & \multicolumn{2}{|c|}{$P$ value $^{\mathrm{a}}$} \\
\hline & & & & Baseline & Week 5 vs. \\
\hline & Baseline & Week 5 & Follow-up & vs. week 5 & follow-up \\
\hline Clostridia (class) & $0.37(0.14-0.58)$ & $0.21(0.08-0.55)$ & $0.41(0.19-0.6)$ & 0.033 & 0.004 \\
\hline Actinobacteria (phylum) & $0.01(0-0.11)$ & $0.07(0.01-0.48)$ & $0.01(0-0.27)$ & 0.008 & 0.064 \\
\hline Actinobacteria (class) & $0.01(0-0.11)$ & $0.06(0-0.48)$ & $0.01(0-0.27)$ & 0.003 & 0.064 \\
\hline Corynebacteriaceae (family) & $0(0-0.05)$ & $0.05(0-0.46)$ & $0(0-0.01)$ & 0.002 & 0.002 \\
\hline Corynebacteriales (order) & $0(0-0.05)$ & $0.05(0-0.46)$ & $0(0-0.02)$ & 0.002 & 0.002 \\
\hline Corynebacterium (genus) & $0(0-0.03)$ & $0.04(0-0.45)$ & $0(0-0.01)$ & 0.001 & 0.006 \\
\hline Pasteurellaceae (family) & $0(0-0.04)$ & $0.01(0-0.35)$ & $0(0-0.02)$ & 0.065 & 0.059 \\
\hline Pasteurellales (order) & $0(0-0.04)$ & $0.01(0-0.35)$ & $0(0-0.02)$ & 0.065 & 0.059 \\
\hline
\end{tabular}




$\begin{array}{llllll}\text { Lentisphaeria (class) } & 0(0-0) & 0(0-0.002) & 0(0-0.002) & 0.371 & 1.000 \\ \text { Victivallales (order) } & 0(0-0) & 0(0-0.002) & 0(0-0.002) & 0.371 & 1.000 \\ \text { Lentisphaerae (phylum) } & 0(0-0) & 0(0-0.002) & 0(0-0.002) & 0.371 & 1.000 \\ \text { Veillonellaceae (family) } & 0.03(0-0.14) & 0.02(0-0.04) & 0.02(0-0.09) & 0.040 & 0.695 \\ \text { Selenomonadales (order) } & 0.04(0.02-0.15) & 0.02(0.01-0.05) & 0.03(0-0.11) & 0.008 & 0.105 \\ \text { Negativicutes (class) } & 0.04(0.02-0.15) & 0.02(0.01-0.05) & 0.03(0-0.11) & 0.008 & 0.105 \\ \text { Clostridiales (order) } & 0.37(0.14-0.58) & 0.21(0.08-0.55) & 0.41(0.19-0.6) & 0.033 & \mathbf{0 . 0 0 4} \\ \text { Firmicutes (phylum) } & 0.48(0.25-0.62) & 0.29(0.14-0.57) & 0.47(0.36-0.77) & 0.005 & \mathbf{0 . 0 0 2} \\ \text { Ruminococcaceae (genus) } & 0(0-0.004) & 0(0-0.001) & 0(0-0) & 0.059 & 0.100 \\ \text { Finegoldia (genus) } & 0.01(0-0.11) & 0(0-0.02) & 0.02(0-0.18) & 0.127 & \mathbf{0 . 0 0 6} \\ \text { Methanobacteria (class) } & 0(0-0) & 0(0-0) & 0(0-0) & 0.371 & 0.181 \\ \text { Methanobacteriaceae (family) } & 0(0-0) & 0(0-0) & 0(0-0) & 0.371 & 0.181\end{array}$




\begin{tabular}{llllll} 
Subdoligranulum (genus) & $0(0-0.09)$ & $0(0-0.02)$ & $0.01(0-0.07)$ & 0.078 & 0.033 \\
Haemophilus (genus) & $0(0-0.04)$ & $0(0-0.29)$ & $0(0-0.01)$ & 0.147 & 0.151 \\
\hline
\end{tabular}

${ }^{a}$ Calculated using a Wilcoxon signed-rank test. 


\section{Supplemental Table 6. Changes in Baseline Relative Abundances of Taxa between Patients With High or Low Gastrointestinal Toxicity}

\begin{tabular}{llll}
\hline Taxa & $\begin{array}{l}\text { High toxicity, median } \\
\text { (range) }\end{array}$ & $\begin{array}{l}\text { Low toxicity, median } \\
\text { (range) }\end{array}$ & $P$ value $^{\mathrm{a}}$ \\
\hline Actinobacteria (phylum) & $0.0046(0.00051-0.013)$ & $0.018(0.0057-0.11)$ & 0.052 \\
Actinobacteria (class) & $0.0042(0.00-0.11)$ & $0.016(0.0049-0.11)$ & $\mathbf{0 . 0 3 0}$ \\
Clostridia (class) & $0.33(0.18-0.35)$ & $0.38(0.29-0.50)$ & $\mathbf{0 . 0 3 0}$ \\
Clostridiales (order) & $0.33(0.18-0.35)$ & $0.38(0.29-0.50)$ & $\mathbf{0 . 0 3 0}$ \\
Clostridiales FamilyXI (family) & $0.10(0.025-0.22)$ & $0.27(0.11-0.33)$ & 0.052 \\
Peptoniphilus (genus) & $0.0040(0.00-0.076)$ & $0.069(0.023-0.16)$ & 0.052 \\
Sellimonas (genus) & $0.00018(0.00-0.00044)$ & $0.00(0.00,0.00)$ & $\mathbf{0 . 0 4 8}$ \\
\hline
\end{tabular}

${ }^{\mathrm{a}}$ Calculated using a Wilcoxon signed-rank test. 


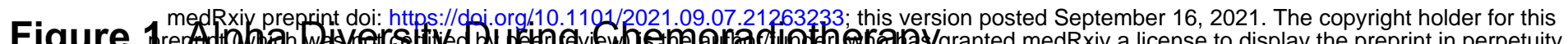
All rights reserved. No reuse allowed without permission.

A. Initiation of Chemoradiotherapy

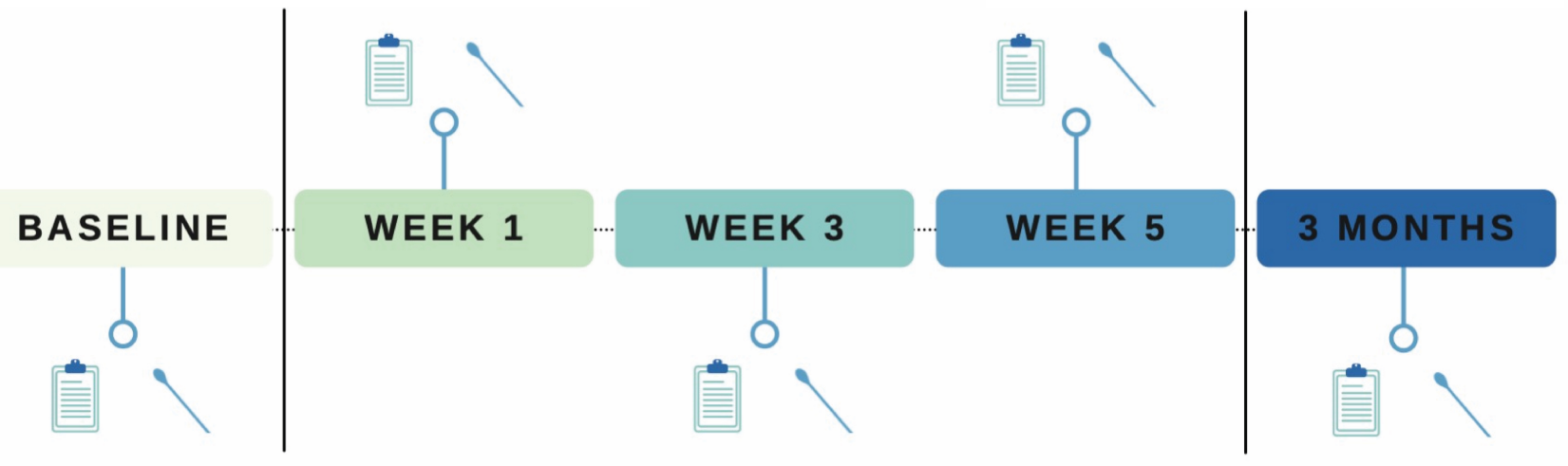

Legend

Patient Reported Outcome Questionnaire

Anal Tumor Swab

B.

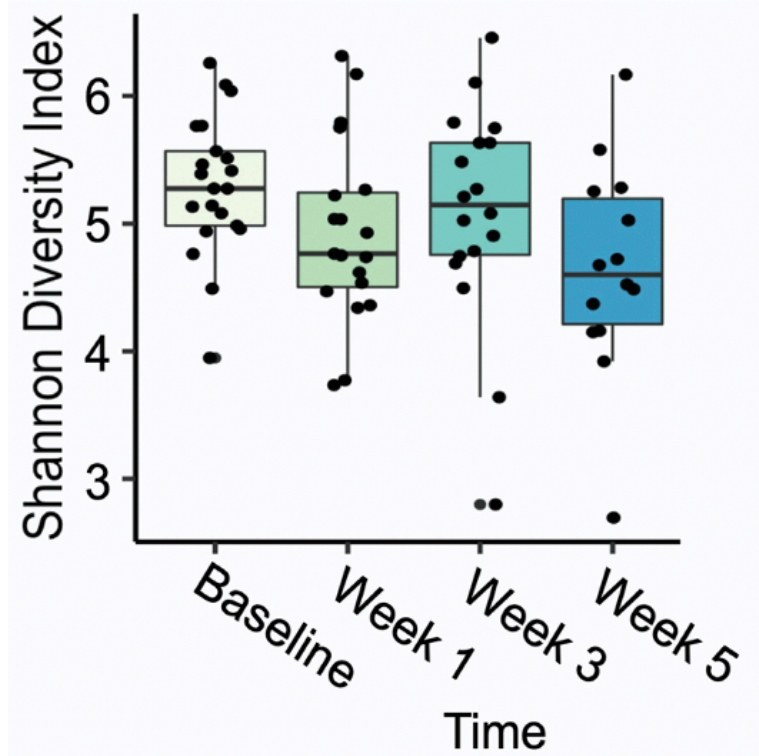

D.

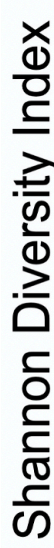

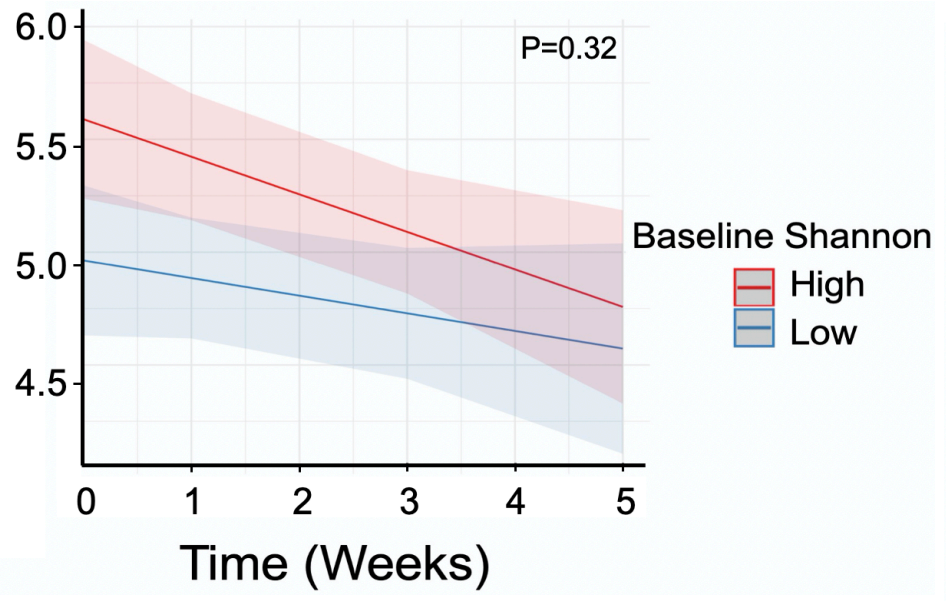

C.

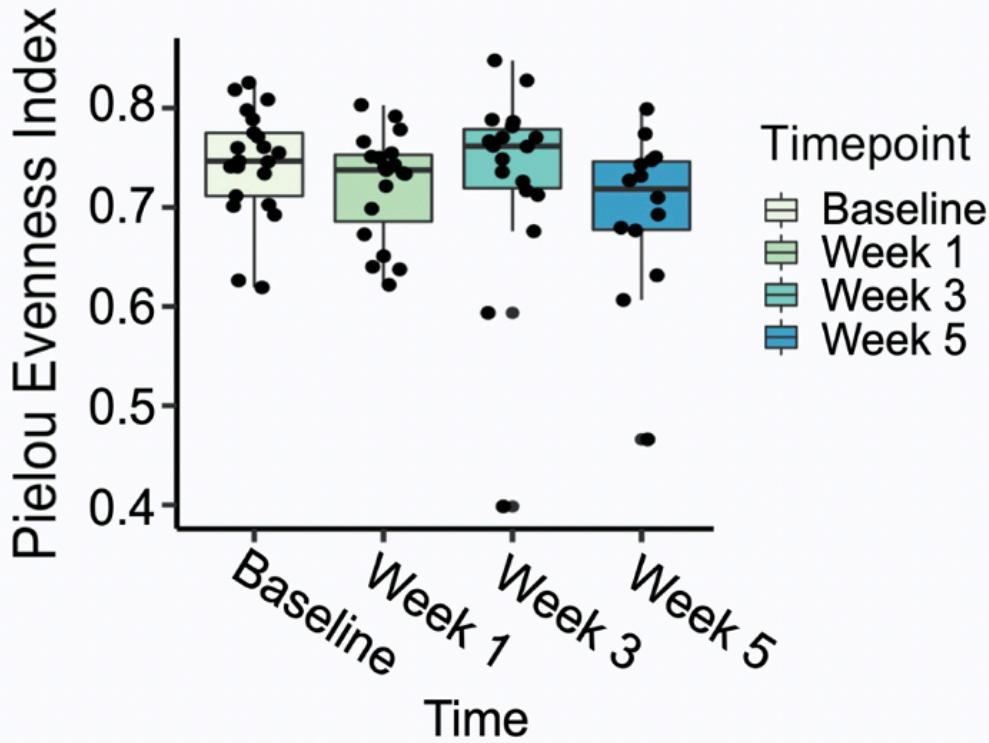

E.

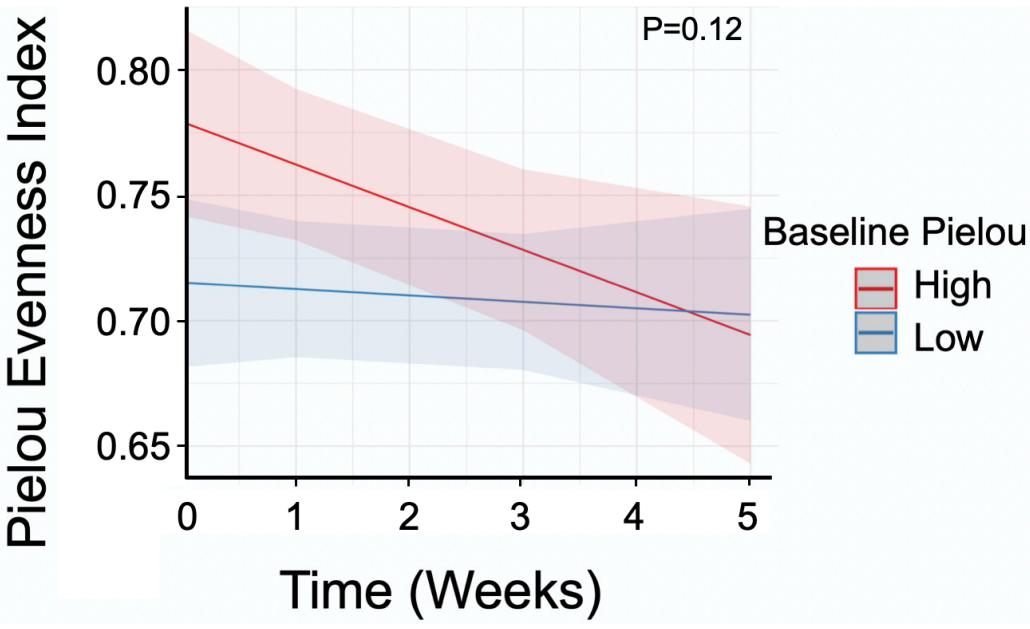




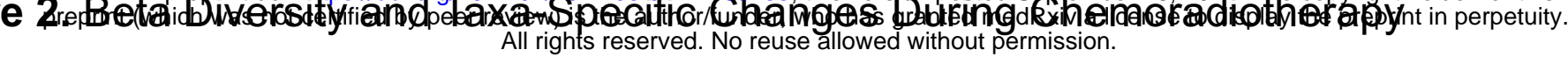

A.

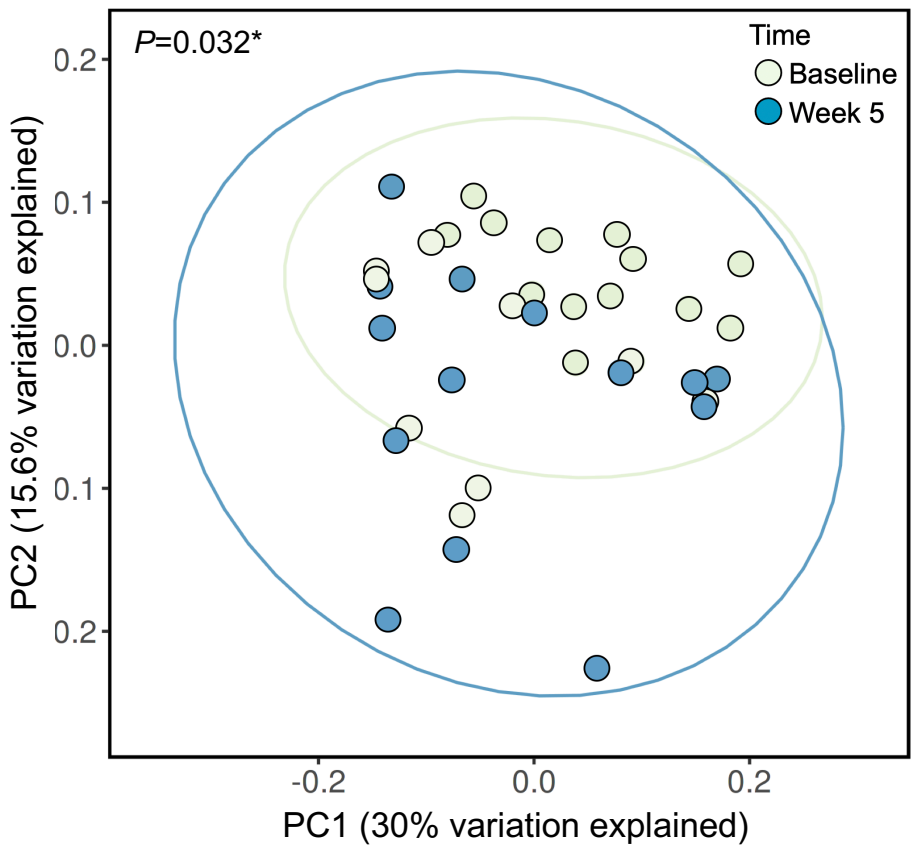

C.

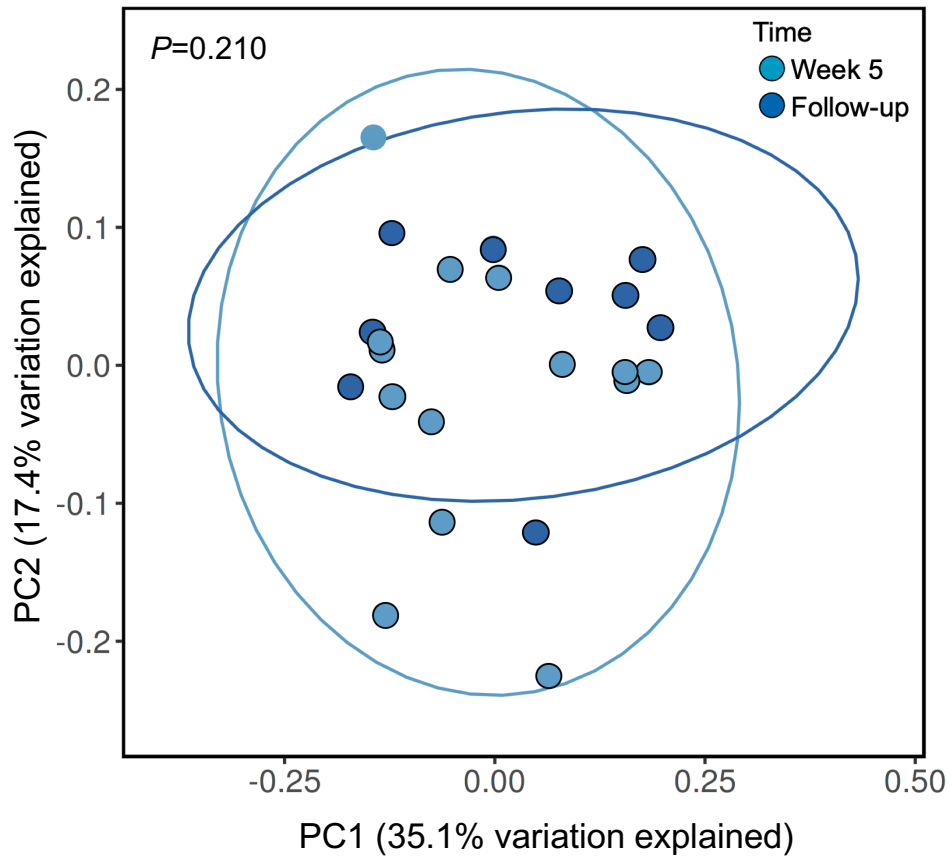

E.

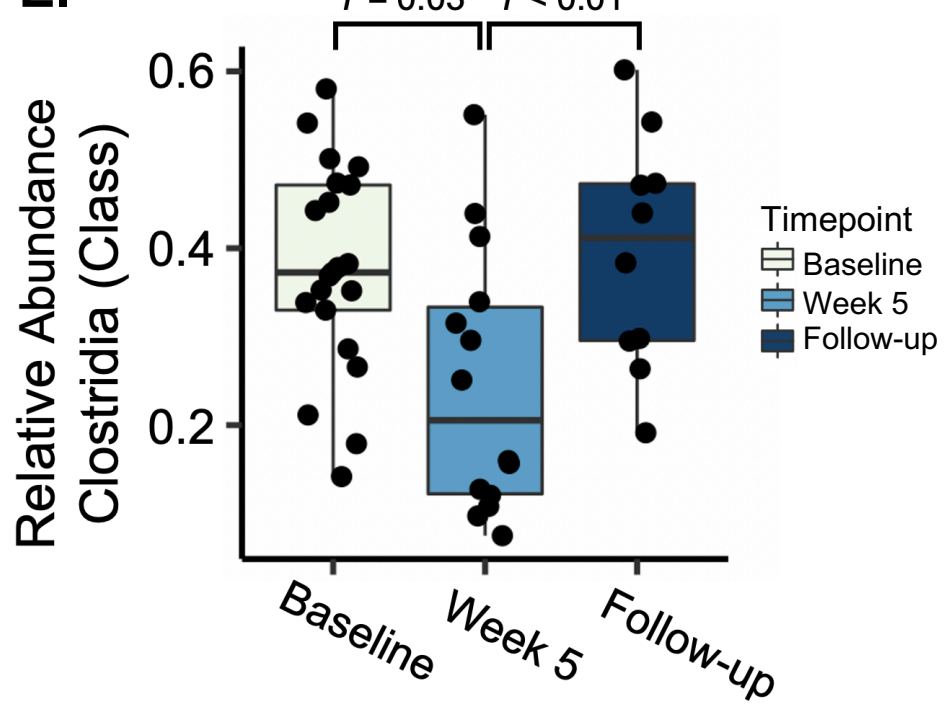

B.

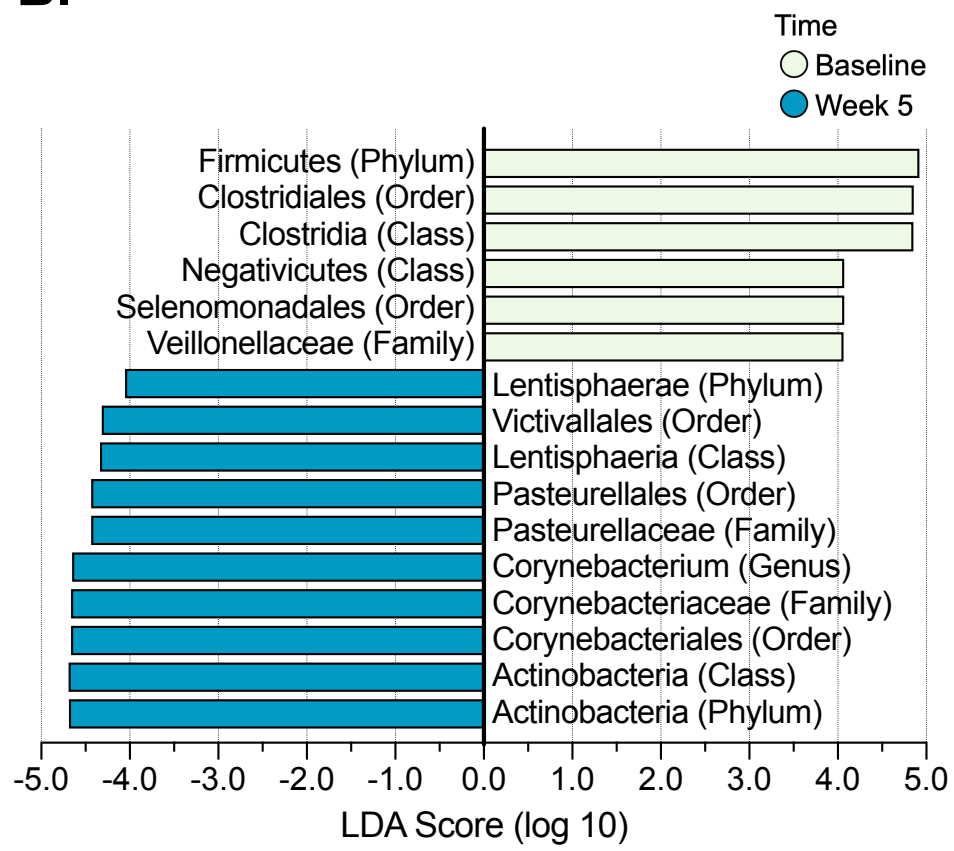

D.

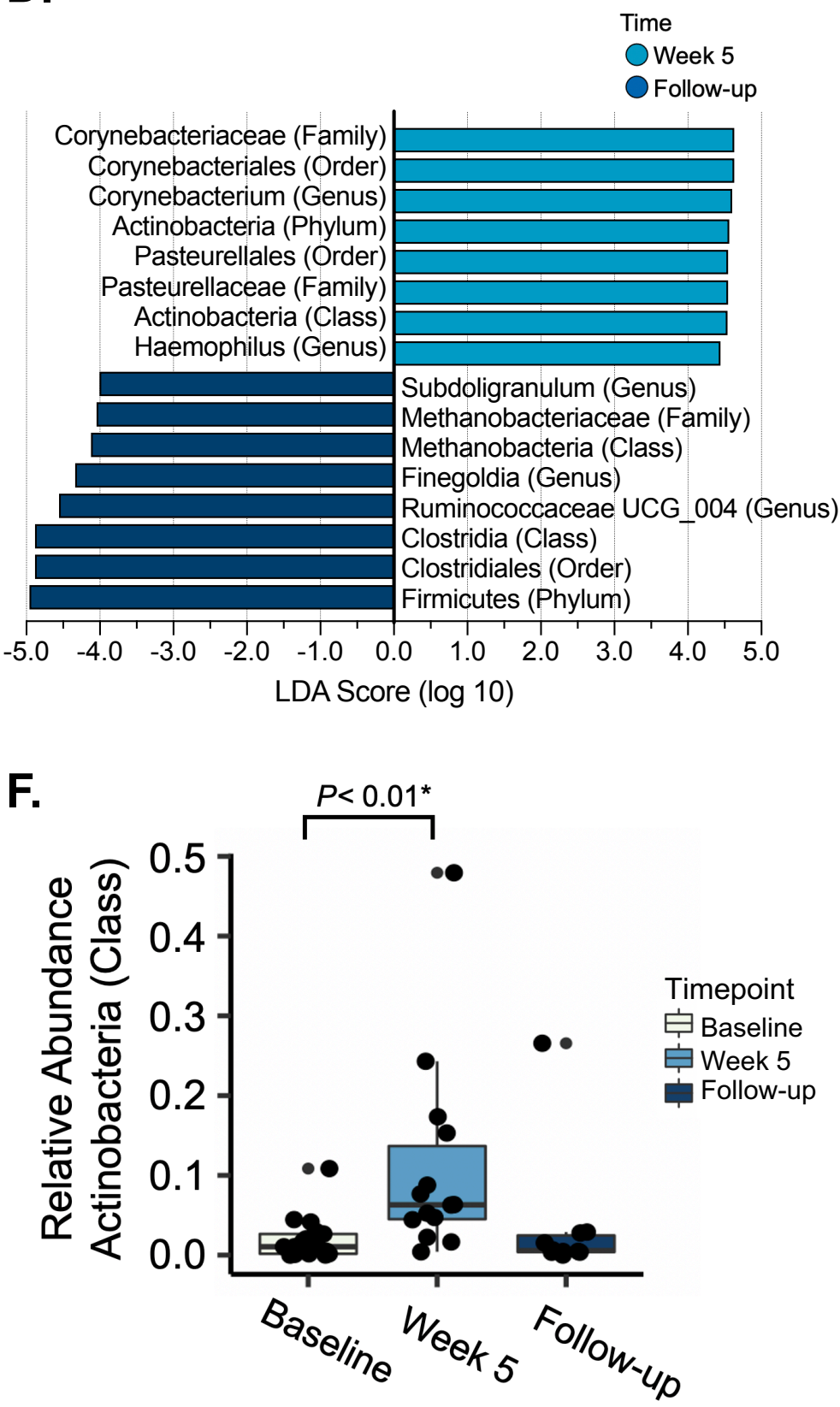




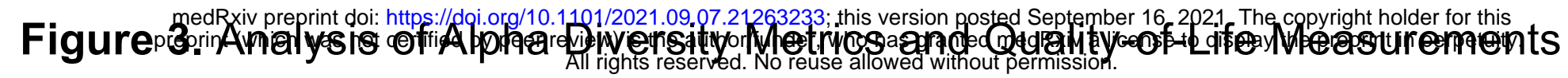
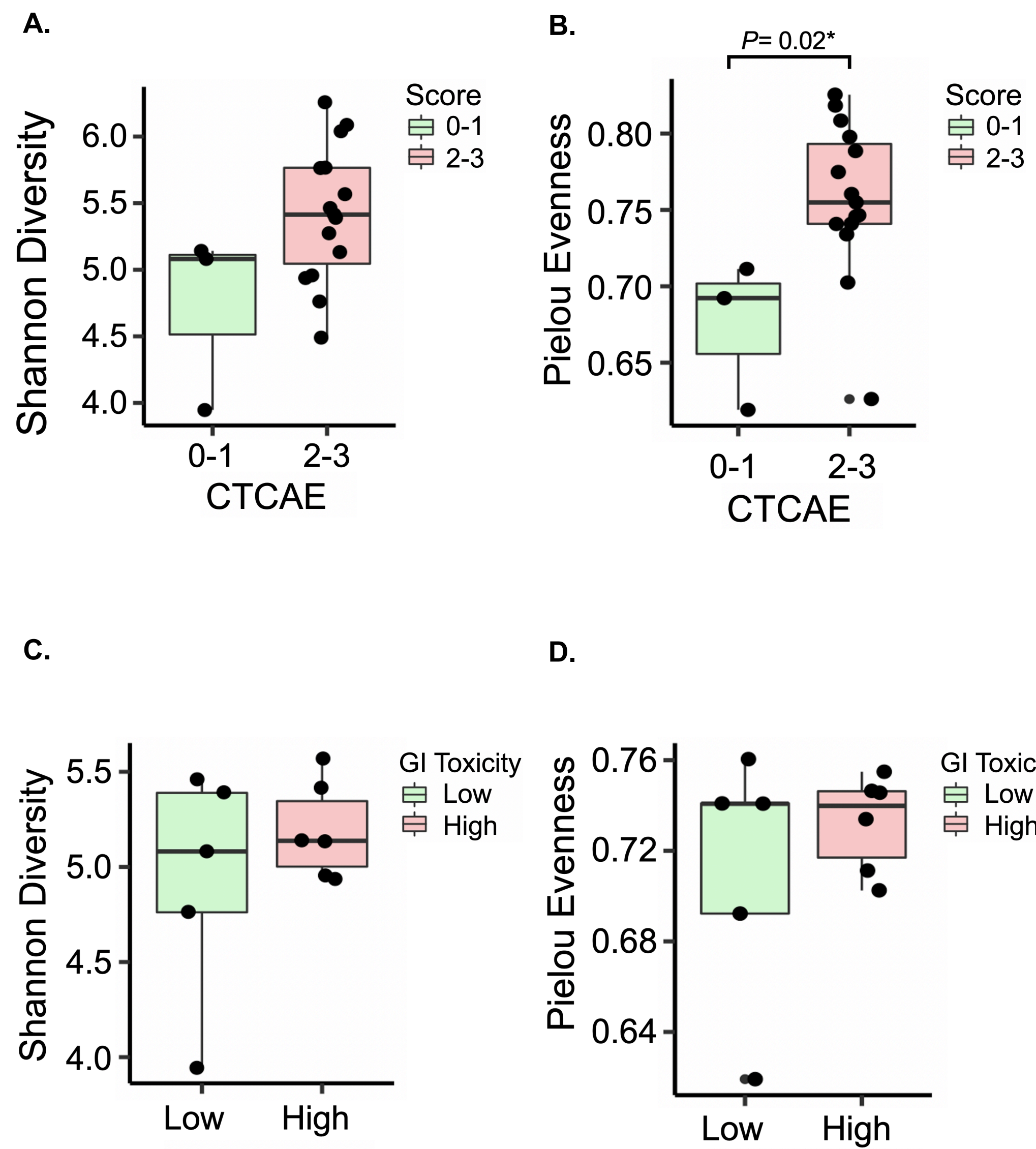

GI Toxicity

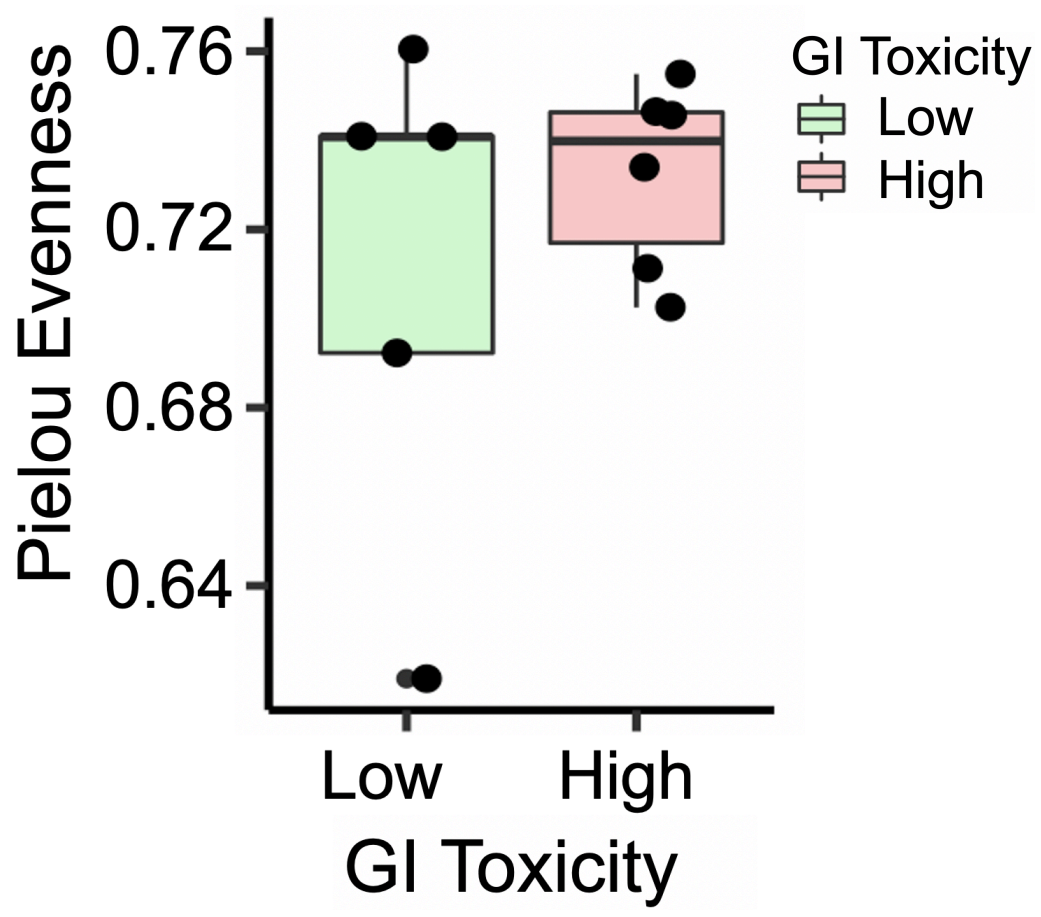




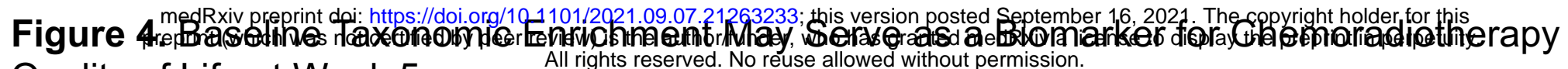

Quality of Life at Week 5

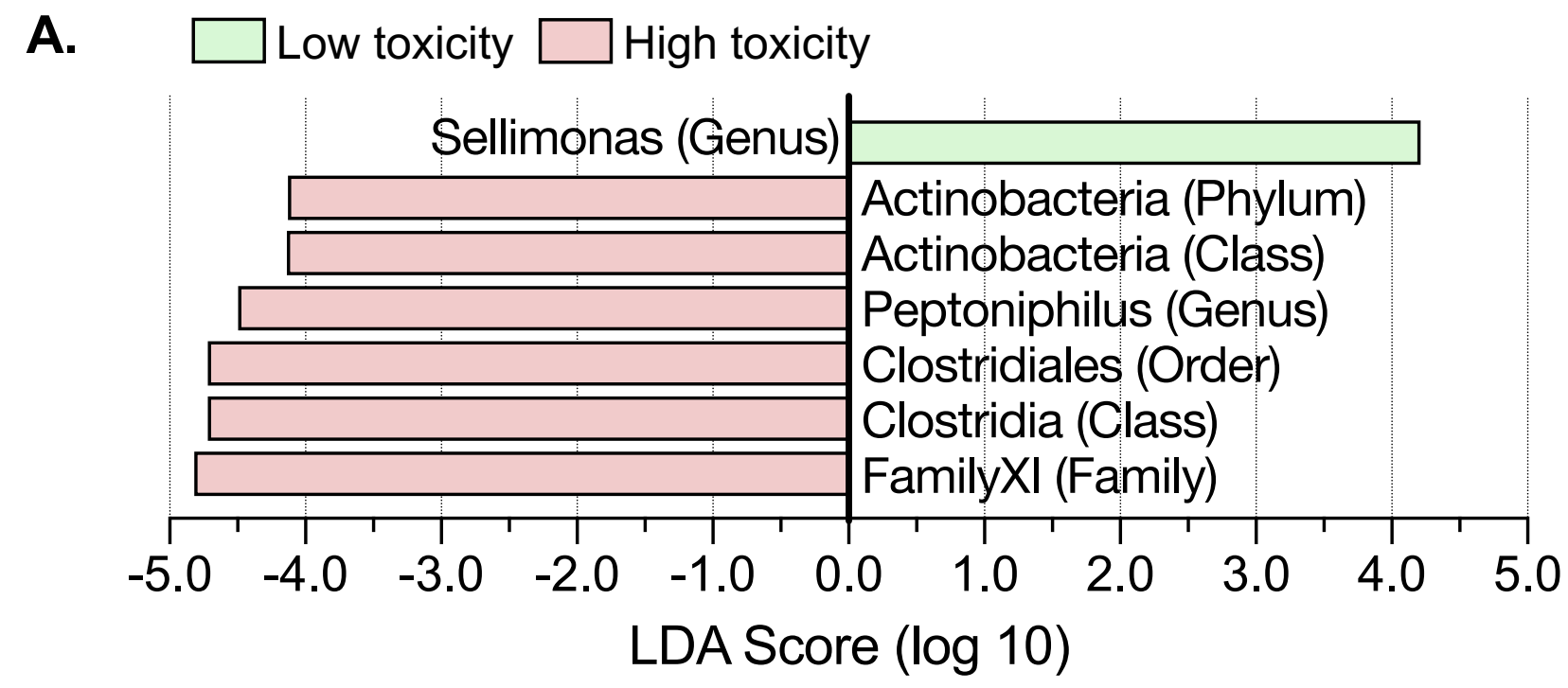

B.

C.
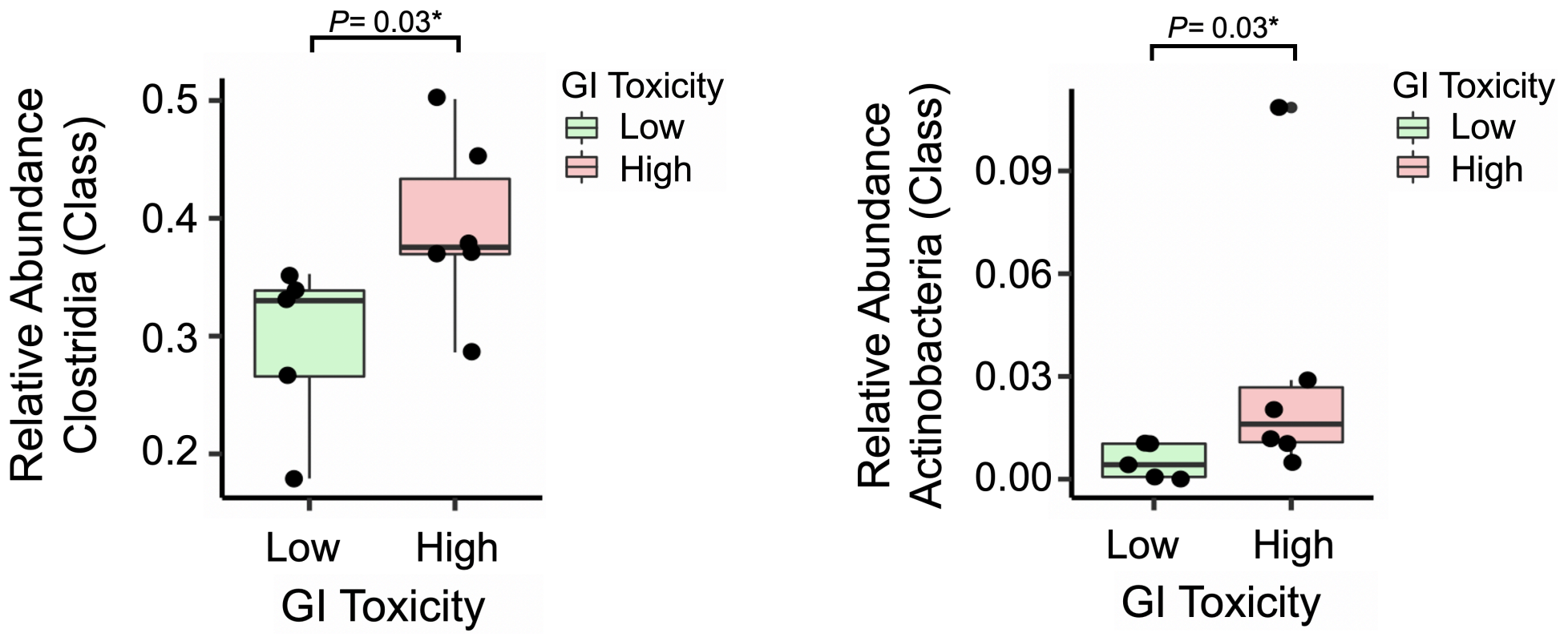